\title{
ESTIMASI OUTPUT BABI DI KABUPATEN TABANAN PROVINSI BALI
}

\section{OUTPUT ESTIMATION OF PIG IN TABANAN REGENCY, BALI PROVINCE}

\author{
Bayu Dewantoro Putro Soewandi*, Sumadi, dan Tety Hartatik \\ Fakultas Peternakan, Universitas Gadjah Mada, Jl. Fauna No. 3, Bulaksumur, Yogyakarta, 55281
}

\section{INTISARI}

Tujuan penelitian ini adalah untuk membuat estimasi output pada babi Bali dan babi Landrace di Kabupaten Tabanan. Penelitian ini dilakukan di lima kecamatan di Kabupaten Tabanan dengan mengambil 150 peternak. Data yang diambil adalah identitas peternak, komposisi, dan reproduksi ternak babi Bali dan babi Landrace. Estimasi output dihitung dengan cara pendekatan teori pemuliaan. Hasil dari penelitian ini diketahui bahwa nilai natural increase babi Bali dan babi Landrace sebesar 60,93 dan 116,38\%. Nilai net replacement rate jantan dan betina babi Bali dan jantan dan betina babi Landrace sebesar 7.664,29 dan $1.844,05 \%$ serta $15.033,33$ dan $1.386,47 \%$. Nilai output pada babi Bali jantan dan betina sebesar 30,78 dan 23,58\% atau 360 dan 114 ekor serta jantan dan betina pada babi Landrace sebesar 45,57 dan 70,49\% atau 6.722 dan 10.009 ekor. Kesimpulan dari penelitian ini adalah estimasi output pada babi Bali jantan $(30,78 \%)$ lebih besar daripada babi Bali betina $(23,58 \%)$, sedangkan pada estimasi output babi Landrace jantan $(45,57 \%)$ lebih kecil daripada babi Landrace betina $(70,49 \%)$.

(Kata kunci: Estimasi output, Babi Bali, Babi Landrace)

\section{ABSTRACT}

The aim of the study was to identify the output of pig on Tabanan regency. The study was conducted at traditional ranch in the civil Tabanan regency. The samples were collected from 150 traditonal breeders in 5 districts. The collection data included identification of breeder, composition and reproduction of Bali and Landrace pig. Estimation output was calculated using teory of breeding approach. The result of the study indicated that the value of natural increase in Bali pigs was $60.93 \%$ and Landrace pigs was $116.38 \%$. The value of net replacement rate in male and female of Bali and Landrace pigs were 7,664.29 and 15,033.33\% and 1,844.05 and 1,386.47\%, respectively. The estimation output male and female Bali pig were 30.78 and $23.58 \%$ (equivalent to 360 and 114 pigs) and male and female Landrace pig 45.57 and $70.49 \%$ (equivalent to 6,722 and 10,009 pigs). Inconclusion, the estimation output in male Bali pig (30.78\%) was bigger than female Bali pig (23.58\%), whereas estimation output in male Landrace pig (45.57\%) was lower than female Landrace pig (70.49\%).

(Key word: Output estimation, Bali pig, Landrace pig)

\section{Pendahuluan}

Indonesia memiliki keanekaragaman spesies babi. Spesies babi yang ada di Indonesia ada lima dari delapan spesies babi yang ada di dunia. Beberapa spesies babi yang ada di Indonesia tersebut beberapa telah mengalami domestikasi. Babi yang telah didomestikasi tersebut telah menjadi babi lokal dan telah dipelihara oleh masyarakat. Salah satu babi lokal yang ada dan masih berkembang sampai saat ini adalah babi Bali. Perkembangan babi Bali masih baik pada saat itu karena babi Bali memiliki keunggulan dapat beradaptasi dengan pola pemeliharaan yang tradisional yaitu dengan pemberian pakan yang seadanya. Keunggulan lain babi Bali adalah kemampuannya mengonsumsi limbah dapur. Babi Bali juga dipakai

\footnotetext{
* Korespondensi (corresponding author):

Telp. +62 87838353496

E-mail: bayu.dewantoro@gmail.com
}

sebagai tabungan bagi masyarakat Bali yang dikenal dengan nama "tatagan banyu" (Suyadnya, 1987). Disamping itu, babi Bali memiliki rasa daging yang lebih enak dibandingkan dengan babi impor. Babi Bali juga memiliki kulit yang lebih crispy saat dibuat makanan babi guling.

Keunggulan-keunggulan yang dimiliki oleh babi Bali tersebut tidak dibarengi dengan performa pertumbuhan dan reproduksi yang baik. Berdasarkan permasalahan tersebut maka pada tahun 1951 pemerintah melakukan impor babi bangsa Landrace (Suyadnya, 1987). Namun seiring berjalannya waktu para peternak babi lebih cenderung memilih babi Landrace dibandingkan dengan babi Bali. Hal ini mengakibatkan terus tergusurnya populasi babi Bali. Babi Bali yang terus tergusur tersebut harus diperhatikan secara serius karena apabila tidak dilakukan penanganan yang tepat yang akan terjadi kepunahan pada babi Bali.

Estimasi output penting dilakukan sebagai langkah awal dalam rangka menghindari kepunahan suatu jenis ternak pada suatu daerah. Hal ini karena 
nilai output dapat digunakan untuk mengatur jumlah pemotongan dan jumlah ternak yang dikeluarkan dari suatu daerah tanpa mengganggu populasi. Perhitungan estimasi output ternak suatu daerah sangat dipengaruhi oleh natural increase dan net replacement rate dari ternak tersebut, sebab output dihitung berdasarkan selisih antara natural increase dengan kebutuhan ternak pengganti selama satu tahun (Hardjosubroto, 1992; Sumadi, 2001). Selain itu estimasi output ternak dapat dipakai untuk mengestimasi pola pembiakan dari suatu ternak di suatu daerah (Hardjosubroto, 1992). Penelitian ini bertujuan untuk mengetahui output pada ternak babi Bali dan Landrace di Kabupaten Tabanan Provinsi Bali.

\section{Materi dan Metode}

\section{Waktu dan lokasi penelitian}

Penelitian dilakukan selama empat bulan mulai bulan Agustus sampai November 2012 di Kabupaten Tabanan, Provinsi Bali. Lima kecamatan yang dipakai dalam penelitian yaitu Kecamatan Penebel, Kediri, Selemadeg, Selemadeg Barat, dan Pupuan. Kelima kecamatan dipilih berdasarkan kepadatan populasi dari ternak babi Bali di kecamatan.

\section{Materi penelitian}

Materi penelitian adalah responden peternak babi Bali dan peternak babi Landrace di Kabupaten Tabanan. Masing-masing kecamatan dari lima kecamatan, diambil 30 responden, sehingga total responden adalah 150 responden.

\section{Metode penelitian}

Penelitian ini besifat deskriptif analitis dengan metode survei untuk mengumpulkan data primer dan sekunder. Cara pengumpulan data primer dilakukan dengan wawancara langsung kepada peternak responden, sedangkan data sekunder diambil dari Dinas Peternakan di Kabupaten Tabanan.

Data primer yang diambil meliputi identitas peternak dan data reproduksi ternak babi. Data identitas dari peternak meliputi umur peternak, pengalaman lama beternak, tingkat pendidikan, tujuan pemeliharaan, dan sistem pemeliharaan yang dilakukan. Data reproduksi ternak babi Bali dan babi Landrace yang diambil terdiri dari perkawinan, lama induk dan pejantan yang digunakan dalam pembiakan, kelahiran, kematian, jumlah ternak yang disurvei, dan struktur populasi. Data sekunder yang dikumpulkan adalah data populasi, pemasukan, pengeluaran, dan pemotongan dari Dinas Peternakan Kabupaten Tabanan.

\section{Analisis data}

Data yang diperoleh dianalisis pada masingmasing bangsa dengan cara: data identitas peternak dianalisis secara deskriptif kualitatif. Data identitas ternak dianalisis dengan menghitung persentase dan rata-rata sehingga dapat menghasilkan koefisien teknis yang dapat digunakan untuk menghitung natural increase, net replacement rate, dan output ternak babi. Rata-rata pemilikan ternak babi Bali dan babi Landrace per peternak per tahun dihitung dengan rumus:

$\mathrm{P}_{\mathrm{aw}}=\mathrm{P}_{\mathrm{ak}}+\mathrm{D}+\mathrm{G}-\mathrm{B}-\mathrm{E}$

$\mathrm{P}_{\mathrm{t}}=\frac{\mathrm{P}_{\mathrm{aw}}+\mathrm{P}_{\mathrm{ak}}}{2}$

$\bar{X}=\frac{P t}{R}$

\section{Keterangan:}

$$
\begin{array}{ll}
\overline{\mathrm{X}} & =\begin{array}{l}
\text { pemilikan ternak rata-rata per peternak } \\
\text { responden per tahun (ekor) }
\end{array} \\
\mathrm{Pt} & =\begin{array}{l}
\text { jumlah sampel babi rata-rata setahun } \\
\text { (ekor) }
\end{array} \\
\mathrm{R} & =\text { jumlah peternak } \\
\mathrm{P} . \mathrm{aw} & =\text { jumlah sampel babi pada awal tahun } \\
& \text { atau setahun sebelum pengamatan } \\
\mathrm{P} . \mathrm{ak} \quad=\begin{array}{l}
\text { jumlah sampel babi pada akhir tahun } \\
\text { (pada waktu pengamatan) }
\end{array} \\
\mathrm{D} & =\text { jumlah kematian setahun } \\
\mathrm{G} & =\text { jumlah pengeluaran ternak setahun } \\
\mathrm{B} & =\text { jumlah kelahiran anak setahun } \\
\mathrm{E} & =\text { jumlah pemasukan ternak selama } \\
& \quad \text { setahun }
\end{array}
$$

Natural increase (NI)

$\mathrm{NI}=\% \mathrm{KlTP}-\% \mathrm{KmTP}$

Keterangan:

$\mathrm{NI}=$ natural increase

$\mathrm{KITP}=$ kelahiran terhadap populasi

$\mathrm{KmTP}=$ kematian terhadap populasi

Keterangan untuk mencari nilai NI pada jenis kelamin (NIjk) tertentu adalah:

$\mathrm{NIjk}=\frac{\text { rasio jenis kelamin tertentu }}{100} \times$ nilai NI total

Ternak pengganti (replacement stock) (TP)

$\mathrm{TP}=\frac{\% \text { komposisi ternak dewasa jenis kelamin tertentu }}{\text { pola pembiakan (lama dalam pembiakan) }}$

Kebutuhan ternak pengganti (net replacement rate atau NRR)

$\mathrm{NRR}=\frac{\mathrm{RTjku}}{\mathrm{TP}} \times 100 \%$ 
Keterangan:

RTjku = ramalan ternak dengan jenis kelamin

$\mathrm{TP}=$ ternak pengganti

Ramalan jumlah tenak dengan jenis kelamin tertentu dalam umur tertentu:

$$
\mathrm{R}=\mathrm{NI}-\mathrm{K}-\mathrm{V}
$$

Keterangan:

$\mathrm{R}=$ ramalan ternak jenis kelamin tertentu dalam umur tertentu

$\mathrm{NI}=$ nilai natural increase $(\mathrm{NI})$ jenis kelamin tertentu

$\mathrm{K}=$ persentase kematian pada saat anak umur tertentu

$\mathrm{V}=$ persentase kematian pada saat umur tertentu

Output pada ternak babi dihitung dengan cara:

$$
\mathrm{OP}=\mathrm{SP}+\mathrm{TAF}
$$

Keterangan:

$\mathrm{OP} \quad=$ nilai output pada babi

$\mathrm{SP}=$ sisa replacement stock

$\mathrm{TAF}=$ ternak afkir baik jantan maupun betina

\section{Hasil dan Pembahasan}

\section{Identitas reponden dan tujuan pemeliharaan}

Pada Tabel 1 menunjukkan bahwa rata-rata umur peternak yang memelihara babi Bali adalah
$51,03 \pm 11,62$ tahun, sedangkan umur peternak babi Landrace relatif sedikit lebih muda yaitu 47,25 $\pm 10,69$ tahun. Umur dari peternak babi Bali dan babi Landrace masih dalam umur yang produktif. Umur produktif berkisar 16 tahun sampai 65 tahun (Widiyanti, 1987). Lama beternak pada peternak babi Bali sebesar 21,30 $\pm 9,24$ tahun dan babi Landrace adalah 13,02 $\pm 10,28$ tahun. Pengalaman beternak merupakan salah satu tolok ukur bagi kemajuan usaha peternakan, karena semakin lama beternak maka peternak akan lebih mampu menyelesaikan kesulitan dan hambatan dalam pengelolaan usahanya (Widiyanti, 1987).

Pada peternak babi Bali tingkat pendidikan formal yang mereka tempuh paling dominan adalah pendidikan SD yaitu sebesar $72,73 \%$, sedangkan para peternak babi Landrace dominan pendidikan SD sebesar 38,46\%. Akan tetapi pendidikan formal peternak babi Landrace juga banyak yang menempuh hingga pendidikan SMA yaitu 33,33\%. Tingkat pendidikan formal yang ditempuh peternak akan berpengaruh pada pengelolaan ternaknya. Tingkat pendidikan sangat berpengaruh terhadap pengelolaan ternak yang dimiliki karena orang yang cenderung pendidikannya lebih baik akan lebih mudah dalam menerima teknologi baru (Lestari, 2000). Pekerjaan utama responden yang memelihara babi Bali dan babi Landrace juga sebagian besar adalah petani dengan persentase masing-masing adalah 81,82 dan $60,68 \%$.

Hasil penelitian tersebut menunjukkan bahwa tujuan utama dalam memelihara babi adalah untuk

Tabel 1. Profil peternak babi di Kabupaten Tabanan, Provinsi Bali tahun 2012 (pig farmer profile in Tabanan Regency, Bali Province 2012)

\begin{tabular}{lcc}
\hline \hline \multicolumn{1}{c}{ Peubah (variable) } & Babi Bali (Bali pig) & Babi Landrace (Landrace pig) \\
\hline Umur peternak (tahun) (farmers old (years)) & $51,03 \pm 11,62$ & $47,25 \pm 10,69$ \\
Lama beternak (tahun) (farmers experience (years)) & $21,30 \pm 9,24$ & $13,02 \pm 10,28$ \\
Pendidikan (\%) (farmers education (\%)) & & \\
Tidak sekolah (uneducated) & 9,09 & 2,56 \\
SD (primary school) & 72,73 & 38,46 \\
SMP (junior high school) & 15,15 & 15,38 \\
SMA (senior high school) & 3,03 & 33,33 \\
Perguruan Tinggi (higher education/University) & 0 & 10,26 \\
Pekerjaan pokok (\%) (job (\%)) & & \\
Petani (farmers) & 81,82 & 60,68 \\
PNS (goverment staff) & 3,03 & 9,40 \\
Wiraswasta (enterpreneur) & 15,15 & 26,50 \\
Pensiunan (retired) & 0 & 3,42 \\
Tujuan Pemeliharaan (\%) (farming aim (\%)) & & \\
Memperoleh keturunan (breeding) & 5,26 & 39,04 \\
Penggemukkan (feedlot) & 84,21 & 47,06 \\
Tabungan (saving) & 2,63 & 11,23 \\
Diambil pupuk (compost) & 7,90 & 2,67 \\
\hline
\end{tabular}


penggemukkan. Kecenderungan peternak babi Bali dalam memelihara ternak babi untuk tujuan penggemukan lebih besar $(84,21 \%)$ dibanding babi Landrace $(47,06 \%)$. Alasan sebagian besar peternak babi memelihara babi untuk penggemukan adalah untuk konsumsi ketika ada upacara agama seperti Galungan dan Kuningan, dimana upacara keagamaan tersebut dilaksanakan setiap 6 bulan sekali.

\section{Komposisi ternak babi}

Tabel 2 menampilkan komposisi dan kepemilikan babi yang ada di Kabupaten Tabanan, Provinsi Bali saat penelitian. Komposisi ternak babi Bali dan Landrace yang dipelihara oleh peternak yaitu anak $44,90 \%$ dan $34,19 \%$, muda $45,18 \%$ dan $44,60 \%$, serta dewasa $9,52 \%$ dan $18,21 \%$.

Berdasarkan komposisi ternak pada Tabel 2, babi Bali muda banyak digunakan untuk tujuan penggemukan. Berdasarkan hasil wawancara dengan beberapa peternak diketahui lama penggemukan berkisar antara 5 sampai 6 bulan. Secara umum komposisi babi muda jantan lebih besar dibandingkan dengan babi muda betina baik pada babi Bali maupun Landrace.

Babi muda jantan lebih besar komposisinya karena digunakan untuk penggemukkan pada saat upacara adat di Kabupaten Tabanan. Babi yang digunakan adalah babi jantan yang dipakai untuk persembahan. Babi tersebut berumur 8 sampai 9 bulan setelah digemukkan selama 5 sampai 6 bulan. Pada peternak babi Bali di Kabupaten Tabanan jarang sekali memelihara babi Bali dewasa yang digunakan sebagai indukan dan pejantan. Hal ini dikarenakan lebih suka membeli babi Bali bakalan dari peternakan babi Bali di daerah Kabupaten Buleleng.

\section{Performa reproduksi ternak babi}

Pada Tabel 3 memperlihatkan bahwa umur pertama kali babi dikawinkan pada babi Bali jauh lebih lambat dibandingkan dengan babi Landrace. Umur pertama kali kawin pada jantan dan betina

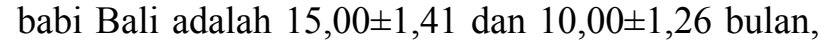
sedangkan babi Landrace umur pertama kali kawin pada jantan dan betina adalah $10,00 \pm 1,87$ dan $8,36 \pm 1,36$ bulan.

Penyebab terlambatnya umur pertama kali kawin ternak babi Bali adalah lambatnya pertumbuhan babi Bali untuk mencapai bobot untuk siap dikawinkan. Lambatnya pertumbuhan tersebut karena pemberian pakan yang kurang dari segi kuantitas maupun kualitasnya. Sihombing (1997) menyatakan bahwa penyebab dewasa kelamin yang lambat adalah faktor pemeliharaan dan pemberian pakan yang kurang dari segi kuantitas maupun kualitas.

Sistem perkawinan yang dilakukan di kabupaten ini pada babi Bali 100\% menggunakan sistem perkawinan alami, namun pada babi Landrace sudah ada yang menggunakan IB. Pada babi Bali sistem perkawinan alami tersebut dikarenakan kurangnya pengetahuan peternak dan juga tidak adanya ketersediaan pejantan untuk

Tabel 2. Komposisi babi Bali dan Landrace di Kabupaten Tabanan, Provinsi Bali tahun 2012 (the composition of Bali and Landrace pig in Tabanan Regency, Bali Province 2012)

\begin{tabular}{lcccc}
\hline \hline \multirow{2}{*}{ Komposisi (composition) } & \multicolumn{2}{c}{ Babi Bali (Bali pig) } & \multicolumn{2}{c}{ Babi Landrace (Landrace pig) } \\
\cline { 2 - 5 } & $\begin{array}{c}\text { Jumlah (ekor) } \\
\text { (number (head) })\end{array}$ & $(\%)$ & $\begin{array}{c}\text { Jumlah (ekor) } \\
\text { (number (head) })\end{array}$ & $(\%)$ \\
\hline Anak (kuncit) (piglet) & & & & \\
Jantan (male) & 20 & 13,61 & 232 & 14,26 \\
Betina (female) & 46 & 31,29 & 328 & 34,19 \\
Jumlah (total) & 66 & 44,90 & & \\
Muda (young) & & & 277 & 23,80 \\
Jantan (male) & 56 & 38,10 & 277 & 23,80 \\
Betina (female) & 11 & 7,48 & 554 & 44,60 \\
Jumlah (total) & 67 & 45,18 & & \\
Dewasa (adult) & & & 13 & 1,12 \\
Jantan (male) & 2 & 1,36 & 199 & 17,09 \\
Betina (female) & 12 & 8,16 & 212 & 18,21 \\
Jumlah (total) & 14 & 9,52 & 456 & 39,24 \\
Total jantan (male total) & 78 & 53,06 & 706 & 60,76 \\
Total betina (female total) & 69 & 46,94 & 1.162 & 100,00 \\
Jumlah (total) & 147 & 100,00 & & \\
\hline
\end{tabular}


Tabel 3. Pengelolaan reproduksi ternak babi di Kabupaten Tabanan, Provinsi Bali tahun 2012 (reproduction management of pig in Tabanan Regency, Bali Province 2012)

\begin{tabular}{lcc}
\hline \multicolumn{1}{c}{ Peubah (variable) } & $\begin{array}{c}\text { Babi Bali (Bali } \\
\text { pig) }\end{array}$ & $\begin{array}{c}\text { Babi Landrace } \\
\text { (Landrace pig) }\end{array}$ \\
\hline Umur pertama kali kawin (bl) (first mating old (month)) & & \\
$\quad$ Jantan (male) & $15,00 \pm 1,41$ & $10,00 \pm 1,87$ \\
Betina (female) & $10,00 \pm 1,26$ & $8,36 \pm 1,36$ \\
Cara kawin (\%) (mating method (\%)) & 100 & \\
Alami (natural) & 0 & 94,37 \\
Inseminasi buatan (IB) (AI) & 0 & 0,63 \\
$\quad$ Campuran (mixed) & $61,67 \pm 16,02$ & $37,93 \pm 11,34$ \\
Umur penyapihan (hari) (old of weaning (days)) & $1,00 \pm 0,00$ & $1,09 \pm 0,30$ \\
Service per conception (S/C) & & \\
Batas umur pemeliharaan (th) (maximum of old to breeding (years)) & $6,50 \pm 2,12$ & $4,20 \pm 1,30$ \\
$\quad$ Jantan (male) & $6,42 \pm 0,49$ & $5,20 \pm 1,50$ \\
Betina (female) & & \\
Lama dalam pembiakan (th) (breeding length (years)) & $5,25 \pm 2,24$ & $3,37 \pm 1,16$ \\
$\quad$ Jantan (male) & $5,58 \pm 0,49$ & $4,51 \pm 1,50$ \\
$\quad$ Betina (female) & $14,67 \pm 1,03$ & $12,29 \pm 1,60$ \\
Umur pertama beranak (th) (first partus old (years)) & $7,00 \pm 1,10$ & $5,89 \pm 0,48$ \\
Jarak beranak (bl) (pigling interval (month)) & $71,33 \pm 27,07$ & $53,99 \pm 13,08$ \\
Post partum mating (hr) (post partum mating (days)) & & \\
Kondisi induk saat melahirkan (\%) (sow condition at pigling (\%)) & 16,67 & 2,98 \\
$\quad$ Kurus (thin) & 50 & 62,69 \\
Sedang (medium) & 33,33 & 34,33 \\
Gemuk (fat) & &
\end{tabular}

diambil semennya di Balai Inseminasi Buatan Babi di daerah Baturiti, sehingga untuk mengawinkan ternaknya para peternak biasanya menyewa pejantan untuk mengawini induk-induk babi yang sedang birahi.

Sistem perkawinan secara alami tersebut juga memberikan pengaruh pada service per conception (S/C). Pada babi Bali diketahui $\mathrm{S} / \mathrm{C}$ adalah $1,00 \pm 0,00$. Hasil $\mathrm{S} / \mathrm{C}$ pada babi Bali ini juga lebih rendah dibandingkan dengan $\mathrm{S} / \mathrm{C}$ pada babi umumnya yaitu 1,6 sampai 2,0 (Sihombing, 1997). Hasil ini lebih rendah dibandingkan hasil penelitian babi lokal yang ada di Kabupaten Timor Tengah Selatan. Service per conception di Kabupaten Timor

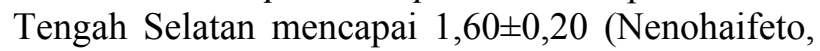
2008). Service per conception pada babi Bali masih lebih baik dibandingkan babi lokal yang ada di Kabupaten Timor Tengah Selatan.

Interval kelahiran pada babi Bali lebih lama dibandingkan babi Landrace. Hal ini dikarenakan umur penyapihan pada babi Bali lebih lama dibandingkan dengan babi Landrace. Interval kelahiran pada babi Bali sebesar 7,00 $\pm 1,10$ bulan dengan umur penyapihan $61,67 \pm 16,02$ hari, sedangkan pada babi Landrace interval kelahiran yaitu $5,89 \pm 0,48$ bulan dengan umur penyapihan $37,93 \pm 11,34$ hari.

Interval beranak kedua bangsa babi tersebut lebih pendek dibandingkan dengan hasil penelitian Pasaribu et al. (1996) yang mendapatkan hasil bahwa interval kelahiran babi di Silando dan Sei Belutu yaitu 8,5 dan 8,2 bulan. Sedangkan penyapihan yang terlalu lama akan berpengaruh pada interval kelahiran sampai birahi pertama sehingga akan menurunkan efisiensi reproduksi yang diharapkan (Salisbury dan Vandemark, 1985). Pada penelitian ini diketahui bahwa anak babi pada babi Bali umur penyapihan lebih lambat. Anak babi disapih pada umur 4 sampai 6 minggu (28 sampai 42 hari) (Sihombing, 1997).

\section{Perhitungan NI, net replacement rate dan output ternak babi}

Natural increase dapat diketahui dengan menghitung selisih antara tingkat kelahiran dan tingkat kematian dalam jangka waktu setahun. Gambaran kenaikan produktivitas ternak terlihat dari naiknya nilai NI. Naiknya nilai NI ini disebabkan oleh adanya perbaikan mutu genetik ternak dan penurunan angka kematian (Hardjosubroto et al., 1990). Pada Tabel 4 tampak bahwa 
Tabel 4. Natural increase babi di Kabupaten Tabanan, Provinsi Bali pada tahun 2012 (NI of pig in Tabanan Regency, Bali Province at 2012)

\begin{tabular}{|c|c|c|}
\hline Peubah (variable) & $\begin{array}{l}\text { Babi Bali (Bali } \\
\text { pig) }\end{array}$ & $\begin{array}{l}\text { Babi Landrace } \\
\text { (Landrace pig) }\end{array}$ \\
\hline \multicolumn{3}{|l|}{ Kelahiran (\%) (birth (\%)) } \\
\hline Total kelahiran terhadap induk (birth total to adult female) & 933,33 & 570,80 \\
\hline Terhadap populasi (birth total to population) & 87,50 & 138,95 \\
\hline $\begin{array}{l}\text { Total kematian terhadap populasi (\%) (mortality total to } \\
\text { population (\%)) }\end{array}$ & 26,57 & 22,57 \\
\hline Natural Increase (\%) & 60,93 & 116,38 \\
\hline Jantan (male) & 32,33 & 45,60 \\
\hline Betina (female) & 28,60 & 70,78 \\
\hline
\end{tabular}

nilai NI babi Bali sebesar $60,93 \%$ dan pada babi Landrace sebesar $116,38 \%$.

Rendahnya nilai NI babi Bali dibandingkan nilai NI pada babi Landrace di daerah Kabupaten Tabanan disebabkan oleh jumlah induk pada babi Bali lebih rendah dibandingkan dengan induk pada babi Landrace. Penyebab lain adalah sedikitnya peternak yang memiliki induk karena sangat banyaknya ternak-ternak muda yang dipelihara oleh peternak dengan tujuan untuk penggemukan dan tidak untuk pembibitan.

Nilai NRR diperoleh dari perbandingan jumlah ternak muda calon pengganti dengan kebutuhan ternak pengganti per tahun dikalikan $100 \%$. Nilai NRR digunakan untuk mengetahui jumlah kelahiran ternak dapat menutupi kebutuhan akan ternak pengganti supaya populasi tidak berubah. Jika nilai NRR $<100 \%$ maka kebutuhan ternak pengganti tidak terpenuhi, sebaliknya bila nilai NRR $>100 \%$ maka kebutuhan ternak pengganti tercukupi (Samberi, 2010).

Nilai NRR babi Bali dan babi Landrace di Kabupaten Tabanan pada tahun 2012 seperti pada Tabel 5. Tabel 5 memperlihatkan bahwa nilai NRR babi Bali jantan dan betina berturut-turut sebesar 9.910,71 dan $1.416,67 \%$ dan pada jantan dan betina babi Landrace nilainya berturut-turut sebesar $12.666,67$ dan $1.773,93 \%$.

Berdasarkan hasil penelitian tersebut tampak bahwa nilai NRR pada babi Landrace jantan dan betina lebih tinggi dibandingkan nilai NRR pada jantan dan betina babi Bali. Hal tersebut disebabkan jumlah jantan dan betina dewasa babi Landrace yang lebih banyak dibandingkan dengan jumlah jantan dan betina dewasa babi Bali sehingga mengakibatkan nilai NRR jantan dan betina babi Landrace lebih tinggi. Berdasarkan perhitungan kebutuhan ternak pengganti ini maka Kabupaten Tabanan, Provinsi Bali dapat menjadi sumber ternak babi Bali maupun babi impor dan di Kabupaten Tabanan dapat dikembangkan babi Bali sebagai sumber plasma nutfah ternak babi lokal di Indonesia.

Potensi babi di suatu daerah adalah banyaknya ternak yang dapat dikeluarkan untuk dijual atau dipotong di suatu daerah tanpa mengganggu populasi di daerah tersebut (Hardjosubroto, 1987). Estimasi output babi Bali di Kabupaten

Tabel 5. Net replacement rate pada babi di Kabupaten Tabanan, Provinsi Bali tahun 2012 (net replacement rate of pig in Tabanan Regency, Bali Province 2012)

\begin{tabular}{lrr}
\hline \hline \multicolumn{1}{c}{ Peubah (variable) } & $\begin{array}{c}\text { Babi Bali (Bali } \\
\text { pig) }\end{array}$ & $\begin{array}{r}\text { Babi Landrace } \\
\text { (Landrace pig) }\end{array}$ \\
\hline $\begin{array}{l}\text { Jantan (male) } \\
\quad \begin{array}{l}\text { Ramalan jantan muda yang hidup umur 1 } \\
\text { male estimation to survive until 1 years (\%)) }\end{array}\end{array}$ & 27,75 & 45,60 \\
$\quad$ Kebutuhan jantan (necessity of male) & 0,28 & 0,36 \\
NRR & $9.910,71$ & $12.666,67$ \\
Betina (female) & & \\
$\quad$ Ramalan betina muda yang hidup umur 1 tahun (\%) (young & 23,80 & 70,78 \\
$\quad$ female estimation to survive until 1 years (\%)) & & \\
$\quad$ Kebutuhan betina (necessity of female) & 1,68 & 3,99 \\
NRR & $1.416,67$ & $1.773,93$ \\
\hline
\end{tabular}


Tabanan, Provinsi Bali pada tahun 2012 disajikan pada Tabel 6.

Estimasi output dikategorikan tinggi apabila persentase kelahiran maksimal dan persentase kematian rendah, karena apabila nilai NI maksimal maka nilai output juga akan ikut maksimal (Oetoro, 1997). Kategori nilai output akan didasarkan pada nilai NI. Pada babi Bali pada penelitian ini rendah (0 sampai 20,31\%), sedang (20,32 sampai 40,62\%) dan tinggi (40,63 sampai 60,93\%). Pada babi Landrace kategori untuk nilai output pada penelitian ini rendah (0 sampai 38,79\%), sedang $(38,80$ sampai $77,58 \%)$ dan tinggi (77,59 sampai $111,38 \%)$.

Pada Tabel 6 dapat diketahui bahwa estimasi output pada babi Bali jantan dan betina adalah 30,78 dan $23,58 \%$, sedangkan estimasi output jantan dan betina babi Landrace adalah 45,57 dan $70,49 \%$. Pada penelitian ini baik pada babi Bali maupun babi Landrace masuk dalam kategori sedang. Rendahnya nilai output baik pada jantan dan betina babi Bali dibandingkan dengan jantan

Tabel 6. Estimasi output babi di Kabupaten Tabanan, Provinsi Bali pada tahun 2012 (output estimation of pig in Tabanan Regency, Bali Province 2012)

\begin{tabular}{lrr}
\hline \multicolumn{1}{c}{ Peubah (variable) } & $\begin{array}{r}\text { Babi Bali } \\
\text { (Bali pig) }\end{array}$ & $\begin{array}{r}\text { Babi Landrace } \\
\text { (Landrace pig) }\end{array}$ \\
\hline $\begin{array}{l}\text { Rasio jenis kelamin kelahiran (jantan : betina) (\%) (sex ratio at birth) } \\
\text { (male : female) (\%)) }\end{array}$ & $53,06: 46,94$ & $39,18: 60,82$ \\
Natural increase (\%) & 60,93 & 116,38 \\
Atas dasar kematian ternak muda maka (\%) (base on young animal & & \\
death (\%)) & 27,75 & 45,60 \\
$\quad$ Jantan pada umur 1 tahun menjadi (male in 1 years) & 23,80 & 70,78 \\
$\quad$ Betina pada umur 1 tahun menjadi (female in 1 years) & & \\
Kebutuhan ternak pengganti (\%) (replacement stock (\%)) & 0,28 & 0,36 \\
$\quad$ Jantan (male) & 1,68 & 3,99 \\
$\quad$ Betina (female) & 27,47 & 45,24 \\
Sisa ternak pengganti (\%) (the rest of the replacement stock (\%)) & 22,12 & 66,79 \\
$\quad$ Jantan (male) & & \\
$\quad$ Betina (female) & 3,31 & 0,33 \\
Persentase ternak afkir (\%) (percentage of culled animal (\%)) & 1,46 & 3,70 \\
$\quad$ Jantan (male) & & \\
$\quad$ Betina (female) & 30,78 & 45,57 \\
Total output (\%) (output total (\%)) & 23,58 & 70,49 \\
$\quad$ Jantan (male) & & \\
$\quad$ Betina (female) & & \\
\hline
\end{tabular}

Tabel 7. Estimasi output babi dalam satuan ekor di Kabupaten Tabanan, Provinsi Bali tahun 2012 (output estimation in head in Tabanan Regency, Bali Province 2012)

\begin{tabular}{lcccc}
\hline \hline \multirow{2}{*}{ Peubah (variable) } & \multicolumn{2}{c}{ Babi Bali (Bali pig) } & \multicolumn{2}{c}{ Babi Landrace (Landrace pig) } \\
\cline { 2 - 5 } & $\begin{array}{c}\text { Jumlah (ekor) } \\
\text { (number) (head) }\end{array}$ & $\%$ & $\begin{array}{c}\text { Jumlah (ekor) } \\
\text { (number) (head) }\end{array}$ & $\%$ \\
\hline $\begin{array}{l}\text { Sisa ternak pengganti (the rest of the } \\
\text { replacement stock) }\end{array}$ & & & & \\
$\quad$ Jantan (male) & 349 & 27,47 & 6.711 & 45,24 \\
$\quad$ Betina (female) & 108 & 22,12 & 9.109 & 66,79 \\
Ternak afkir (culled animal) & & & & \\
$\quad$ Jantan (male) & 11 & 3,31 & 1 & 0,33 \\
Betina (female) & 6 & 1,46 & 900 & 3,70 \\
Total output (output total) & & & & 45,57 \\
Jantan (male) & 360 & 30,78 & 6.722 & 70,49 \\
Betina (female) & 114 & 23,58 & 10.009 & \\
\hline
\end{tabular}


dan betina babi Landrace pada hasil penelitian ini diduga disebabkan oleh rendahnya nilai NI babi Bali dibandingkan nilai NI babi Landrace.

Komposisi output ternak tergantung dari beberapa persen ternak yang harus disingkirkan dan digantikan dengan ternak muda yang dipakai sebagai ternak pengganti (replacement stock) (Hardjosubroto, 1992). Apabila pengeluaran ternak sama dengan NI-nya dalam suatu wilayah maka populasi ternak akan seimbang sehingga dapat dikatakan bahwa output ternak dalam suatu wilayah adalah sama dengan NI-nya.

Berdasarkan populasi babi yang ada di Kabupaten Tabanan pada tahun 2012 dapat diketahui bahwa output ternak babi yang dapat dikeluarkan untuk dijual dan dipotong setiap tahun tanpa mengganggu populasi pada babi Bali jantan dan betina sebesar 360 dan 114 ekor (Tabel 7). Estimasi output jantan dan betina babi Landrace secara umum adalah 28.570 ekor dengan output pada babi Landrace jantan sebesar 6.722 dan babi Landrace betina sebesar 10.009 ekor (Tabel 7).

\section{Kesimpulan}

Kesimpulan dari penelitian ini adalah nilai NI pada babi Bali $(60,93 \%)$ lebih rendah dibandingkan babi Landrace $(116,38 \%)$. Nilai NRR pada babi Bali jantan $(7.664,29 \%)$ lebih rendah daripada babi Bali betina (15.033,33\%), sedangkan pada babi Landrace nilai NRR Babi Landrace jantan $(1.844,05 \%)$ lebih rendah dibandingkan dengan babi Landrace betina $(1.386,47 \%)$. Estimasi output pada babi Bali jantan lebih tinggi (30,78\% setara dengan 360) daripada babi Bali betina $(23,58 \%$ setara dengan 114 ekor), sedangkan babi Landrace jantan (45,57 setara dengan 6.722 ekor) lebih rendah dibandingkan (70,49\% setara dengan 10.009 ekor) tanpa mengganggu populasi.

\section{Daftar Pustaka}

Hardjosubroto, W. 1987. Metode penentuan output ternak yang dapat dipotong dari suatu wilayah (DIY). Laporan Penelitian. Proyek Pengembangan Ilmu dan Teknologi. Direktorat Binlitabmas, Ditjen Dikti Departemen Pendidikan dan Kebudayaan. Fakultas Peternakan. Universitas Gadjah Mada, Yogyakarta.
Hardjosubroto, W. 1992. Pola pembiakan dan output sapi potong di Daerah Istimewa Yogyakarta. Buletin Peternakan 16 : 54-62.

Hardjosubroto, W., P. A. Supriyono, D. Sularsasa, dan Sumadi. 1990. Persentase panen pedet (calf crop) pada sapi potong di Dati II Pati dan Purworejo Jawa Tengah. Laporan Penelitian. Fakultas Peternakan. Universitas Gadjah Mada. Yogyakarta.

Lestari, S. K. 2000. Analisis investasi usaha tani ternak sapi potong yang tergabung dalam kandang kelompok. Skripsi. Fakultas Peternakan. Universitas Gadjah Mada. Yogyakarta.

Nenohaifeto, W. N. I. 2008. Estimasi natural increase ternak babi di Kabupaten Timor Tengah Selatan Provinsi Nusa Tenggara Timur. Skripsi. Fakultas Peternakan. Universitas Gadjah Mada. Yogyakarta.

Oetoro. 1997. Peluang dan tantangan perkembangan sapi potong. Prosiding Seminar Nasional Peternakan dan Veteriner. Pusat Penelitian dan Pengembangan Pertanian. Departemen Pertanian. Bogor.

Pasaribu, T., M. Silalahi, D. Aritonang, dan K. Manhuruk. 1996. Pengaruh pemberian konsentrat selama prapartum dan menyusui terhadap kinerja anak babi di Peternakan Rakyat. Jurnal Ilmu Ternak dan Veteriner 1: 169-173.

Salisbury dan M. I. Vandemark. 1985. Fisiologi Reproduksi dan Inseminasi Buatan Pada Sapi. Gadjah Mada University Press. Yogyakarta.

Samberi, K. Y., N. Ngadiyono, dan Sumadi. 2010. Estimasi dinamika populasi dan produktivitas sapi Bali di Kabupaten Kepulauan Yapen, Propinsi Papua. Buletin Peternakan 34: 169177.

Sihombing, D. T. H. 1997. Ilmu Ternak Babi. Gadjah Mada University Press. Yogyakarta.

Sumadi. 2001. Estimasi dinamika populasi dan output kambing Peranakan Ettawah di Kabupaten Kulon Progo. Buletin Peternakan 25: 161-171.

Suyadnya, I. P. 1987. Peningkatan produksi anak babi Bali melalui superovulasi dan pemacuan. Disertasi. Fakultas Pasca Sarjana Institut Pertanian Bogor. Bogor.

Widiyanti, N. 1987. Ledakan Penduduk Menjelang Tahun 2000. Bina Aksara. Jakarta. 